\title{
5 Minutos de Programação em Exibições
}

\author{
Christiane Gresse von Wangenheim ${ }^{1}$, Aldo von Wangenheim ${ }^{1}$, Fernando S. \\ Pacheco $^{2}$, M. Nathalie F. Ferreira ${ }^{1}$, Jean C. R. Hauck ${ }^{1}$ \\ ${ }^{1}$ INCoD - Departamento de Informática e Estatística - Universidade Federal de Santa \\ Catarina (UFSC) - Florianópolis - SC - Brazil \\ ${ }^{2}$ Instituto Federal de Santa Catarina (IFSC) - Florianópolis - SC - Brazil \\ c.wangenheim@ufsc.br, aldo.vw@ufsc.br, fspacheco@ifsc.edu.br, nathalie@incod.ufsc.br; \\ jean.hauck@ufsc.br
}

\begin{abstract}
In order to popularize computing in a playful way at science fairs, we created an exhibit to demystify physical computing and at the same time to motivate and stimulate interest in computing. We designed two minion-shaped interactive programmable robots (one more than one meter high) that in a recreational way show how easy and interesting it can be to create programs in a few minutes in a drop-in setting. The robots are visually programmed via a Scratch 2/Snap! program and automated by an Arduino Nano microcontroller in a simple, low-cost, platform-independent way. Our experience at SEPEX 2015 with more than 4,000 visitors shows that offering such exhibits to the general public can be an engaging alternative for popularizing computing in an inexpensive way.
\end{abstract}

Resumo. Para popularizar a computação de maneira lúdica em feiras científicas, criamos um estande para desmistificar a computação física e, ao mesmo tempo, motivar e estimular o interesse pela computação. Foram projetados dois robôs programáveis interativos, em forma de minion (um deles com mais de um metro de altura). Com ambos, pode-se mostrar como é fácil e interessante criar programas em poucos minutos utilizando uma linguagem visual como Scratch 2 ou Snap!. O hardware consiste em uma placa microcontrolada Arduino Nano e um conjunto de sensores e atuadores. A experiência na SEPEX 2015, com mais de 4 mil visitantes, mostra que a oferta de tais estandes ao público em geral pode ser uma alternativa envolvente para popularizar a computação com um custo baixo.

\section{Introdução}

A popularização da computação entre o público em geral, especialmente para crianças, tornou-se uma preocupação crescente. Atualmente, em várias profissões, a necessidade de conhecimento em computação não se limita simplesmente às habilidades básicas em tecnologia da informação. Torna-se cada vez mais importante ter uma certa fluência em computação [CSTA 2011], demonstrando habilidades básicas em pensamento computacional e programação [Gresse von Wangenheim et al. 2017]. Portanto, o ensino de computação para crianças em oficinas, acampamentos, tutoriais on-line ou dentro de seu contexto escolar tem se tornado recentemente uma tendência na educação. Existem várias iniciativas no Brasil com foco no ensino da computação na escola, como, por exemplo, a Iniciativa Computação na Escola (http://computacaonaescola.ufsc.br), e o Programa Meninas Digitais (http://meninasdigitais.sbc.org.br), além de outras 
experiências [Silva et al. 2016], [Pinho et al. 2016], [Batista et al. 2015], [Silva de Oliveira et al. 2014].

Especialmente para crianças, o emprego de computação física ou robótica tem despertado grande interesse. Essa área multidisciplinar integra o mundo virtual com o real utilizando sensores e atuadores. Várias iniciativas têm direcionado crianças a aprender computação utilizando robôs [Padri and Chernova 2013], [O'Sullivan \& Igoe 2004], [Bers and Urrea 2000] ou sensores e atuadores [Physical 2016], em atividades práticas e divertidas [Eguchi 2010],[Benitti 2012]. O ensino de computação física é tipicamente realizado no contexto escolar, seja em aulas regulares, como atividades de clubes extraclasse ou ainda como parte de desafios e competições como a RoboCupJunior [Robocup 2016].

Exposições em feiras ou museus podem ser consideradas formas alternativas de popularizar a computação, nas quais é possível atingir um público mais amplo e diversificado. Essas exposições oferecem ao público uma oportunidade de se envolver com a educação de maneira informal. Ao contrário da escola, eles são voluntárias, abertas e flexíveis. Os locais são frequentemente visitados por famílias, casais ou grupos de amigos como parte de atividades recreativas e/ou por excursões escolares como uma viagem de campo. A vantagem de exposições é que podem fornecer experiências emocionantes, fornecendo informações básicas e estimulando o interesse e a curiosidade por computação.

A fim de serem motivadoras e envolventes, exposições precisam fornecer experiências interativas, criando oportunidades para os visitantes explorarem e experimentarem atividades de pensamento computacional e/ou programação por si mesmos. No entanto, vários fatores têm de ser levados em consideração [Ucko 1985]. Como os visitantes são livres para escolher onde ir, o que fazer e o tempo de interação (ao contrário das configurações de sala de aula), exposições eficazes devem ser convidativas e de fácil compreensão [Falk et al. 2007]. Um público heterogêneo, sem experiência prévia, deve ser capaz de compreender o propósito da atividade, escopo e propriedades quase que imediatamente e sem esforço consciente [Allen 2004]. Além disso, deve ser curta e estimulante para manter a atenção e motivação dos visitantes durante todo o processo de interação [Humphrey et al. 2005], [Pekarik e tal. 1999]. Deve também criar mais interesse e o desejo de continuar aprendendo dentro e fora da escola [Maton-Howarth 1990]. Todas estas questões devem ser abordadas, mantendo os custos de desenvolvimento, aquisição e manutenção baixos [Horn et al. 2008].

Neste contexto, uma alternativa de baixo custo, que se popularizou nos últimos anos, é o emprego de placas eletrônicas com microcontroladores ou microprocessadores, como Arduino [Arduino 2016], Raspberry Pi [RaspberryPi 2016] ou GogoBoard [Blikstein 2013], [Karim et al. 2015]. Entretanto, a carência de ferramentas/interfaces amigáveis exige do público leigo um razoável conhecimento de eletrônica e computação [Vandevelde et al. 2013], algo que pode criar uma barreira de acesso e desmotivar esse público. Uma das barreiras é a programação usando linguagens de nível mais baixo, em modo texto, com vários detalhes e particularidades de sintaxe [Vandevelde et al. 2013]. O uso de linguagens visuais de drag-and-drop, como Scratch ou Snap! é fundamental para facilitar o processo de programação e apresentar uma interface mais atraente para o público geral [Vandevelde et al. 2013]. 
Além das questões de custo e facilidade de uso, ao fazer uma observação mais atenta do público e das iniciativas de ensino de computação física, percebe-se que as aplicações de robótica muitas vezes diminuem o interesse das meninas por focarem na construção de carros ou robôs de batalha [Rusk et al. 2008], [Mitnik, Nussbaum \& Soto 2008], [Benitti 2012]. Assim, para envolver o maior grupo possível é benéfico ir além do tradicional carrinho, criando atividades mais abrangentes, por exemplo, com marionetes ou esculturas interativas [Rusk et al. 2008], [Yanco et al. 2007], [Bers 2007].

Levando então em consideração essas questões criamos, como parte da nossa iniciativa Computação na Escola, um estande para desmistificar a computação física (especialmente a programação) e, ao mesmo tempo, motivar e estimular o interesse em aprender mais sobre computação. Foi desenvolvido um conjunto de atividades interativas recreacionais, mostrando como pode ser fácil e interessante criar programas usando ambientes de programação visuais. O público-alvo da exposição são crianças do ensino fundamental, mas nossa experiência mostrou que os adolescentes e adultos também se interessaram pelas atividades.

\section{Robô Programável Interativo}

Para chamar a atenção dos visitantes, exploramos a atratividade da computação física com um robô programável interativo em forma de minion (http://dictionary.cambridge.org/pt/dicionario/ingles/minion). O robô, com pouco mais de um metro de altura, acompanha os visitantes com os olhos (detectando sua presença por meio de sensores de ultrassom), levanta o braço para oferecer uma banana, acende um LED da arma de brinquedo e faz diferentes barulhos (https://www.youtube.com/watch?v=IVsh5Wyp-Ms).

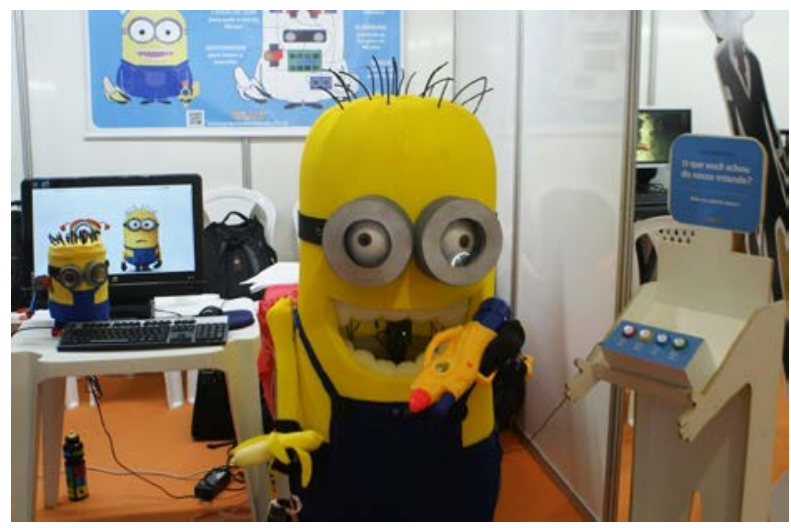

Figura 1. Robôs programáveis interativos no estande

O robô é programado usando Scratch 2 [Scratch 2007] ou Snap! [Harvey e Mönig 2015], comandando um microcontrolador Arduino Nano. A fim de permitir uma melhor visualização do funcionamento do robô, além de facilitar a compreensão e aprendizagem, foram desenvolvidas duas ferramentas especiais para a construção e o controle de dispositivos físicos por Scratch/Snap!:

- Scratchboard (www.computacaonaescola.ufsc.br/scratchboard): uma placa de conexão para o Arduino Nano, de baixo custo e fácil de usar, que permite 
construir rapidamente dispositivos físicos, com componentes ligados por conectores telefônicos.

- Scratchduino (www.computacaonaescola.ufsc.br/scratchduino): uma extensão da linha de comando s2a_fm (Scratch para Firmata), um tradutor de protocolo originalmente desenvolvido por Yorinks (2013). Isso também facilitou a conexão ao Scratch e Snap! em oficinas de computação física realizadas no Brasil [Gresse von Wangenheim et al. 2017]. A Figura 2 ilustra a integração dessas ferramentas.
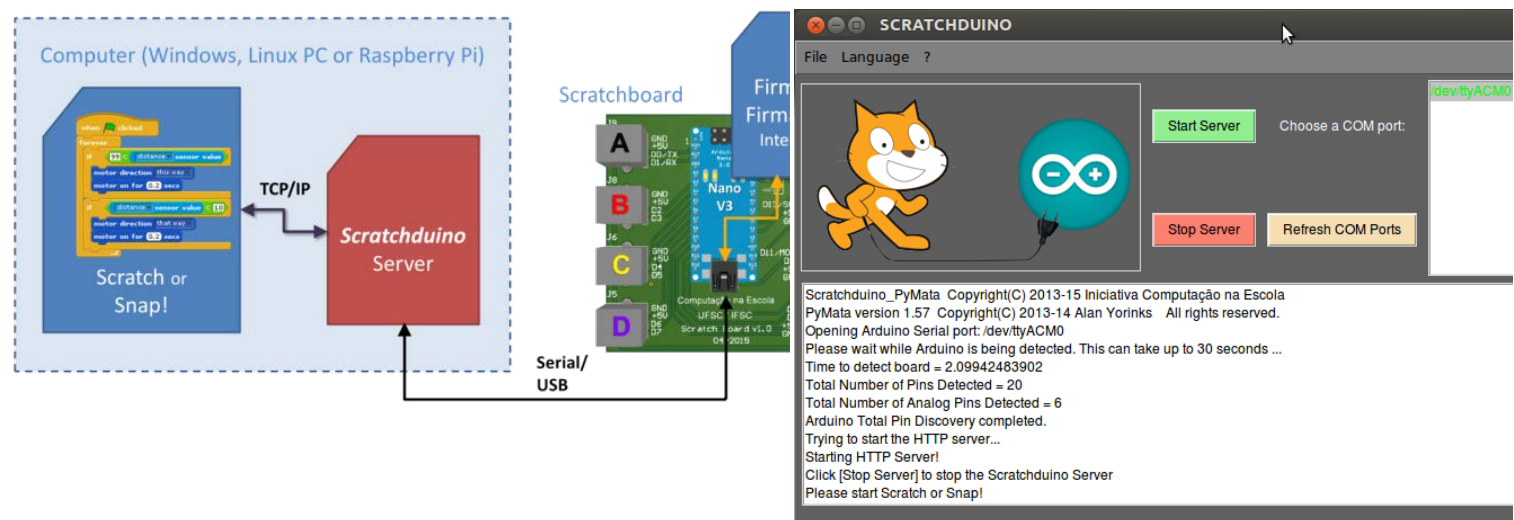

Figura 2. Esquema operacional do Scratchduino/Scratchboard e Scratchduino GUI

Este ambiente é usado para programar o controle de vários componentes de hardware (LEDs, sensor de ultrassom, motor) do robô ilustrado na Figura 3.

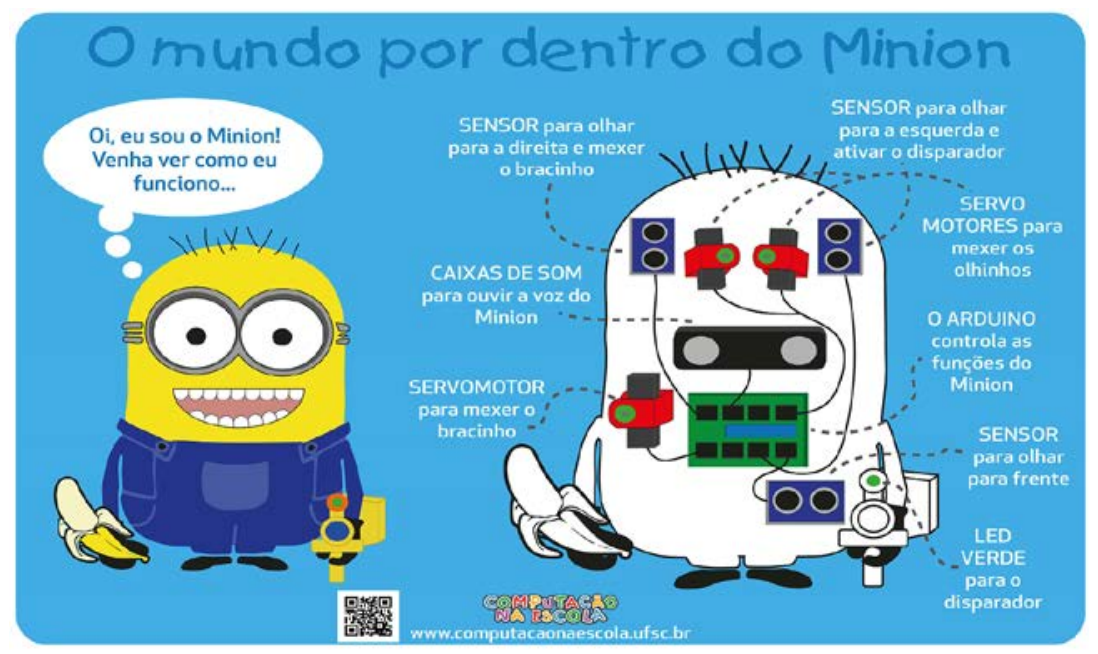

Figura 3. O robô por dentro

As funções do robô podem ser facilmente programadas usando Scratch 2 [Scratch 2007] ou Snap! [Harvey e Mönig, 2015] (Figura 4). 


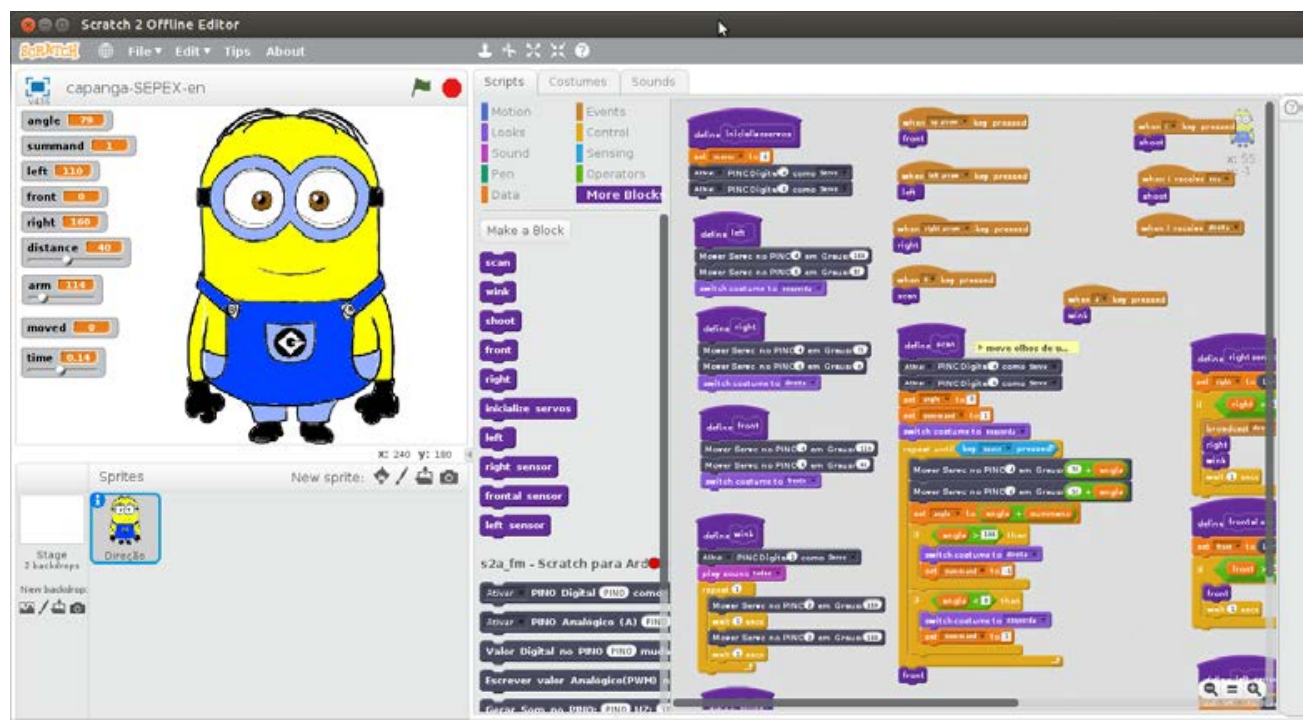

Figura 4. Programa SCRATCH que controla o robô

A fim de permitir que os visitantes da feira pudessem experimentar ativamente a programação, também foi criada uma versão menor do minion - um robô que ilumina os olhos, move o braço, fala e canta.

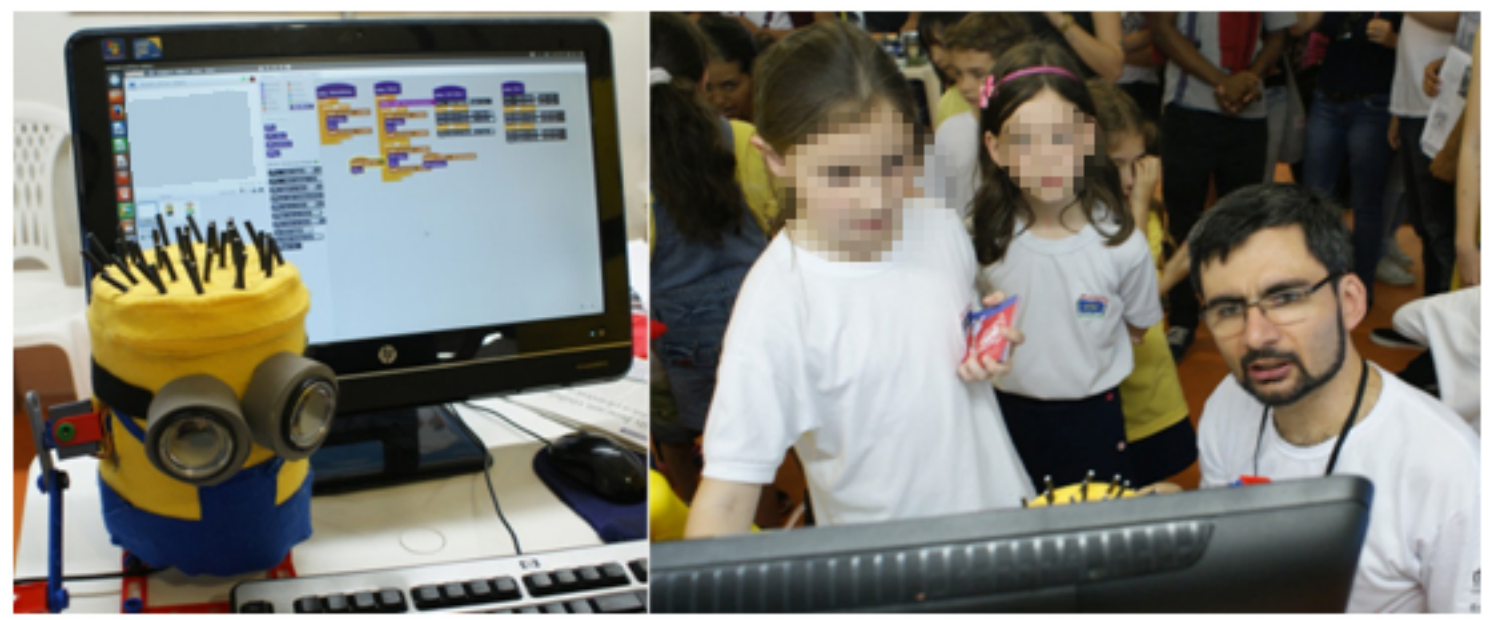

Figura 5. Visitantes do estande interagindo com a versão pequena do robô

Ambos os robôs foram construídos com baixo custo por quatro pesquisadores em menos de 25 horas, com um custo total de menos de US\$ 250 para o robô grande e US\$ 90 para o menor. 

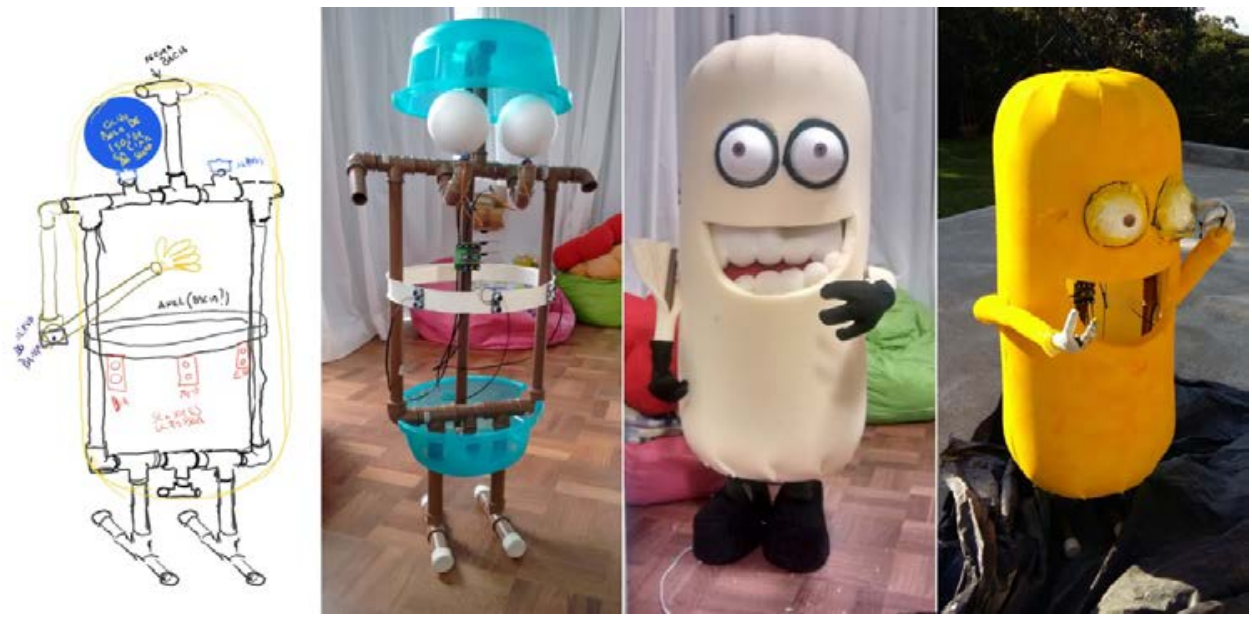

Figura 6. Construção do robô grande

Tabela 1. Custos do Robô

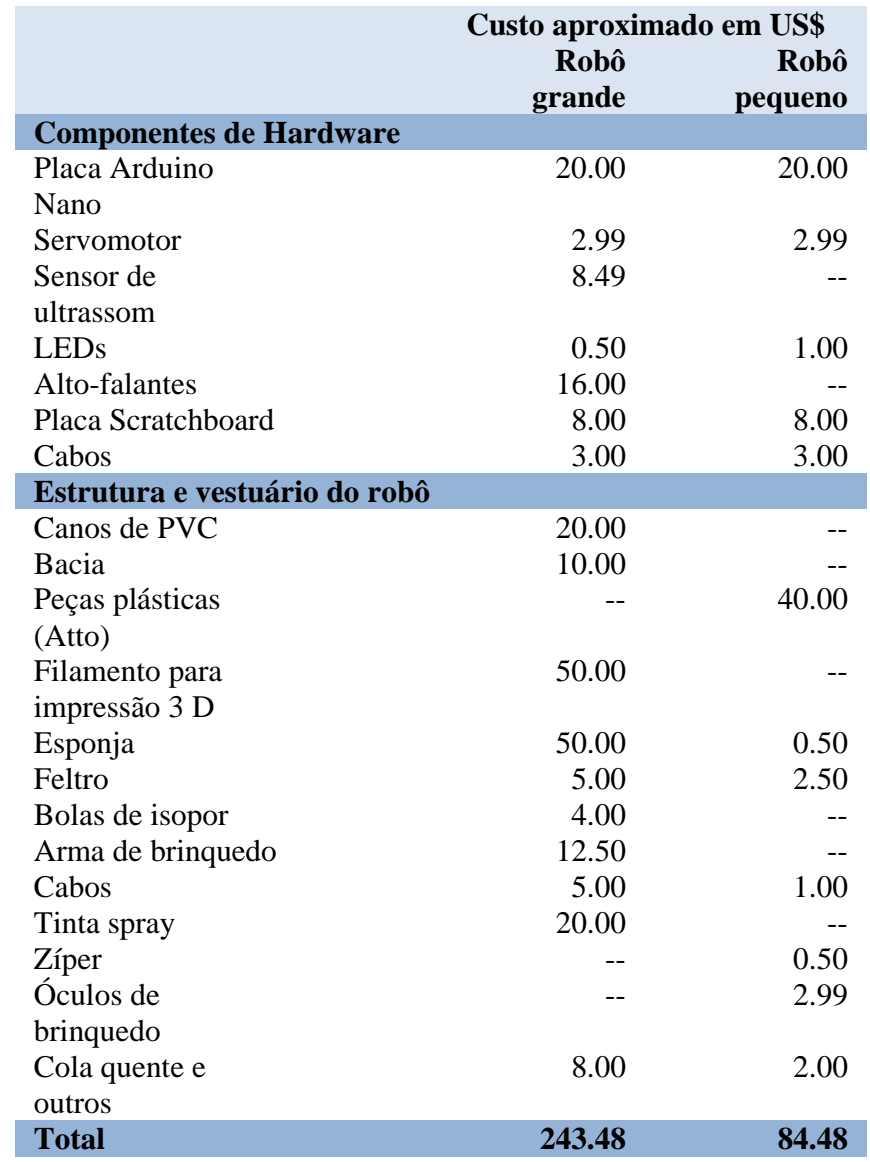

\section{Experiência de Aplicação}

Os robôs foram apresentados na Semana de Ensino, Pesquisa e Extensão (SEPEX) (http://sepex.ufsc.br) na Universidade Federal de Santa Catarina, de 11 a 14 de novembro de 2015 em Florianópolis, um dos maiores eventos de divulgação científica 
do Estado de Santa Catarina. Durante a SEPEX, nosso estande foi visitado por aproximadamente 4 mil pessoas, incluindo muitas turmas de escolas de ensino fundamental e médio. Como um evento aberto ao público em geral, também foi visitado por muitos pais com filhos, estudantes universitários e professores. Observamos que o estande atraiu também muitas meninas (as de menor idade, mas também as do ensino médio), que pareciam especialmente atraídas pelo robô grande.
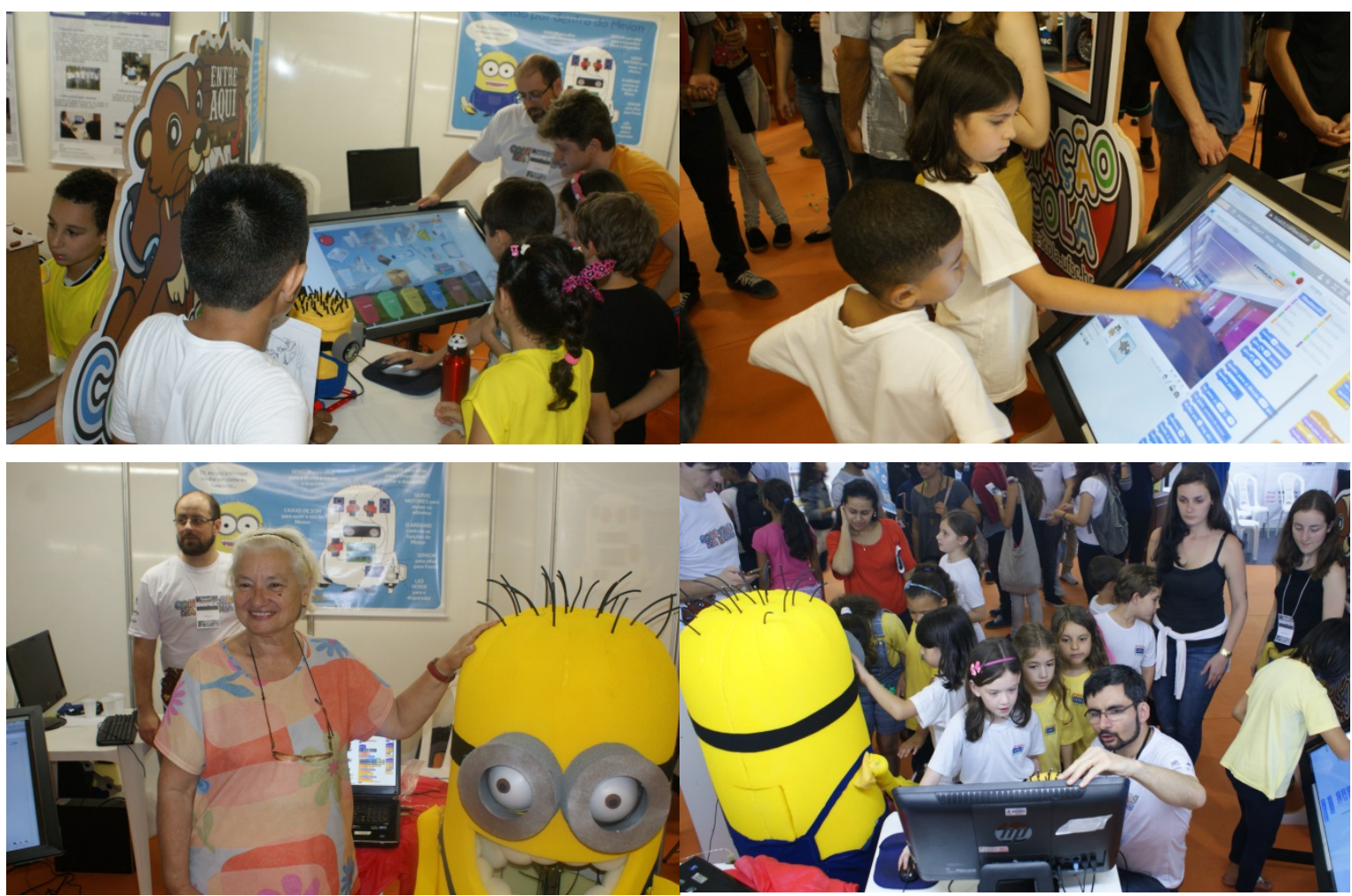

Figure 7. Visitantes no estande

Os robôs customizados foram considerados uma maneira convidativa para atrair visitantes. Várias crianças chegavam à entrada da feira já perguntando onde encontrar os minions. Também presenciamos a curiosidade dos visitantes que passavam no corredor e trazendo também outras pessoas para mostrar os robôs.

Com relação aos objetivos de aprendizagem, observamos que foi muito fácil para as crianças (até mesmo para as menores) entender comandos simples do programa que controla os robôs. Sob a orientação dos facilitadores, os visitantes puderam mudar as ações robô pequeno, experimentando assim primeiras experiências de programação. Conceitos de programação foram apresentados de forma informal, não adotando uma metodologia instrucional formal.

O grau de engajamento com a exposição variou largamente. Alguns visitantes apenas se aproximaram da exposição para tirar uma foto com o robô, ou observaram passivamente outros visitantes interagindo com os robôs. Outros apenas estavam interessados em conhecer o estande, computação e/ou nossa iniciativa. No entanto, um grande número parou para interagir ativamente com o estande, para entender 0 programa e tentar mudar as ações dos robôs, programandos-os. Os visitantes 
permaneceram no estande aproximadamente de 1 a 15 minutos. Algumas crianças também retornavam várias vezes para continuar a explorar o estande.

Medindo a satisfação dos visitantes por meio de um terminal de feedback simples com quatro botões, foi possível verificar que a grande maioria dos visitantes que deixaram sua opinião considerou o estande excelente (Fig. 8).

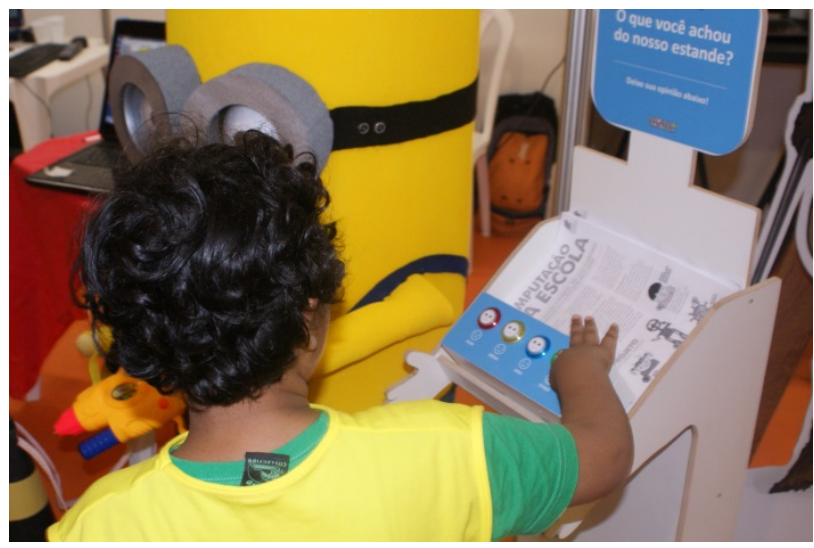

Figura 8a. Medidor de opinião

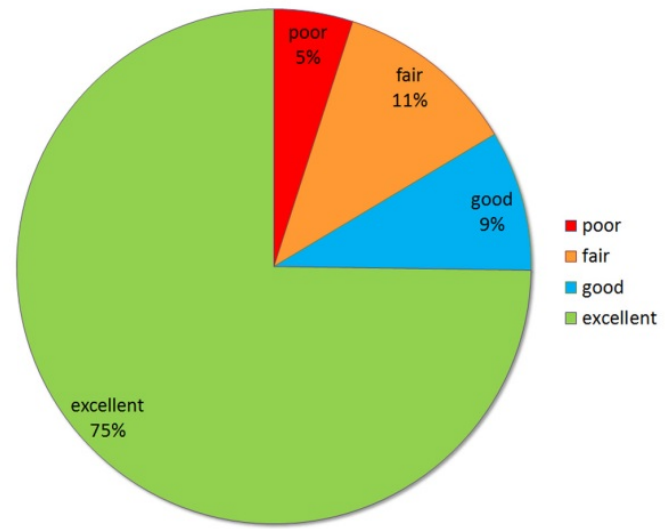

Figura 8b. Avaliação dos visitantes do estande

Foi possível observar também que a experiência no estande estimula o interesse pela computação, já que muitos visitantes (crianças e adultos) perguntavam como poderiam aprender mais por meio de aulas ou oficinas, além de buscarem informações para levar atividades dessa natureza para suas escolas.

\section{Conclusão}

A experiência relatada mostra que a oferta de tais estandes ao público em geral pode ser uma alternativa convidativa, apreensível e atraente para popularizar a computação com baixo custo. É claro que nessas experiências de 5 minutos não se espera que as pessoas aprendam a programar e, portanto, não enfoca no ensino de robótica e conceitos de programação, mas sim em dar aos visitantes uma experiência positiva e prática que possa inspirá-los para aprender mais sobre programação de computadores e robótica. Em geral o objetivo do estande é que os visitantes se afastem pensando: "Eu programei um robô hoje! Consigo fazer isso! Foi divertido e eu quero aprender mais!”.

\section{Agradecimentos}

Agradecemos a todos os membros da iniciativa Computação na Escola que ajudaram durante a SEPEX. Este trabalho foi financiado pelo CNPq (Conselho Nacional de Desenvolvimento Científico e Tecnológico), uma entidade do governo brasileiro focado no desenvolvimento científico e tecnológico, do Programa da Iniciação à Pesquisa Institucional (BIPI/UFSC) e do programa Google Rise Award.

\section{Referências}

Allen, S. (2004). Designs for Learning: Studying Science Museum Exhibits That Do More Than Entertain. Science Education - Wiley Periodicals, 88, S1, S17-S33. 
Arduino (2016). https://www.arduino.cc/. Dezembro.

Batista, E. J. S., et al. (2015). Utilizando o Scratch como ferramenta de apoio para desenvolver o raciocínio lógico das crianças do ensino básico de uma forma multidisciplinar. In: Anais do XXII Workshop sobre Educação em Computação, Recife/PE.

Benitti, F. B. V. (2012) "Exploring the educational potential of robotics in schools: A systematic review”. Computers \& Education, 58(3), p. 978-988.

Bers, M. U. (2007) "Project InterActions: A Multigenerational Robotic Learning Environment.” Journal on Science Education and Technology, 16, p. 537-552.

Bers, M. U. and Urrea, C. (2000) "Technological prayers: parents and children exploring robotics and values”. In: Robots for kids: exploring new technologies for learning. Edited by A. Druin \& J. Hendler.

Blikstein, P. (2013) "Gears of Our Childhood: Constructionist Toolkits, Robotics, and Physical Computing, Past and Future”. (IDC), New York, NY, USA.

CSTA Standards Task Force (2011). “CSTA K-12 Computer Science Standards”. New York, NY, USA.

Eguchi, A. (2010) "What is educational robotics? Theories behind it and practical implementation". In: Proc. of the Int. Conf. of the Society for Information Technology \& Teacher Education, Chesapeake, VA, USA, p. 4006-4014.

Falk, J.H., Dierking, L.D., Foutz, S. (eds.) (2007). In Practice: Museums as Learning Institutions. AltaMira Press, Lanham, MD.

Gresse von Wangenheim, C., von Wangenheim, A., Pacheco, F. S., Hauck, J. C. R., Ferreira, M. N. F. Teaching Physical Computing in Family Workshops. ACM Inroads, 8(1), 48-51, 2017.

Harvey, B. and Mönig, J. (2015). "Snap! (Build Your Own Blocks) 4.0”. http://snap.berkeley.edu/ Novembro.

Horn, M.S., Solovey, E. T., Jacob, R.J.K. (2008). Tangible Programming and Informal Science Learning: Making TUIs Work for Museums. In Proceedings of the 7th International Conference on Interaction Design and Children, Chicago, IL/USA.

Humphrey, T. et al. (2005). Fostering Active Prolonged Engagement: The Art of Creating APE Exhibits. Left Coast Press.

Karim, M. E., Lemaignan, S., Mondada, A. (2015) "Review: Can robots reshape K-12 STEM education?”. In: Proc. of the 2015 IEEE International Workshop on Advanced Robotics and its Social Impacts, Lyon, France.

Maton-Howarth, M. (1990). "Knowing objects through an alternative learning system”. In S. Pearce (ed.) Objects of Knowledge. London: The Athlone Press, 174-203.

Mitnik, R., Nussbaum, M., and Soto, A. (2008) "An autonomous educational mobile robot mediator". Autonomous Robots, 25(4), p. 367-382.

National Research Council (2009) Learning science in informal environments: People, places, and pursuits. The National Academies Press, Washington, DC. 
O'Sullivan, D. and Igoe, T. "Physical Computing - Sensing and Controlling the Physical World with Computers, Boston”. MA: Thomson Course Technology. 2004.

Padir, T. and Chernova, S. (2013) "Guest Editorial - Special Issue on Robotics Education”. IEEE Transactions on Education, 56(1), p. 1-2.

Pekarik, A. et al. (1999). Exploring Satisfying Experiences in Museums. Curator: The Museum Journal, 42(2), 152-173.

Pinho, G. et al. (2016). Pensamento Computacional no Ensino Fundamental: Relato de Atividade de Introdução a Algoritmos. In: Anais do XXII Workshop sobre Educação em Computação, Uberlândia/MG.

Physical Computing with Raspberry Pi. https://www.raspberrypi.org/help/physicalcomputing/

Raspberrypi (2016). https://www.raspberrypi.org/. Dezembro.

Robocup Junior (2016). http://rcj.robocup.org/. Dezembro.

Rusk, N. et al. (2008) "New pathways into robotics: Strategies for broadening participation”. Journal of Science Education and Technology, 17(1), p. 59-69.

Scratch (2007). Scratch - Imagine, Program, Share. https://scratch.mit.edu/. Dezembro.

Silva de Oliveira, M. L. et al. (2014) Ensino de lógica de programação no ensino fundamental utilizando o Scratch: um relato de experiência. In: Anais do XXII Workshop sobre Educação em Computação, Brasília/DF.

Silva, T. R. et al. (2016). Um relato de experiência da aplicação de videoaulas de programação de jogos digitais para alunos da educação básica. In: Anais do XXII Workshop sobre Educação em Computação, Uberlândia/MG.

Ucko, D. A. (1985). Science Literacy and Science Musem Exhibits. Curator - the Museum Journal, 28(4), 287-300.

Vandevelde, C. et al. (2013) "Overview of technologies for building robots in the classroom”. In: Proc. of the Int. Conference on Robotics in Education, Lodz, Poland, p. 122-130.

Yanco, H. A. et al. (2007) "Artbotics: Combining Art and Robotics to Broaden Participation in Computing”. In: Proc. of the AAAI Spring Symposium: Semantic Scientific Knowledge Integration.

Yorinks, A. (2013). MrYsLab/s2a_fm. https://github.com/MrYsLab/s2a_fm. Novembro. 